\title{
IN-PALCO MOSTRA DE DANCCA INCLUSIVA: EVENTO, INCLUSÃO E RELAÇÕES PÚBLICAS
}

\author{
IN-PALCO INCLUSIVE DANCE SHOW: \\ EVENT, INCLUSION AND PUBLIC RELATIONS
}

\author{
Fernanda Sagrilo Andres ${ }^{1}$ e Carol Moreira ${ }^{2}$
}

\section{RESUMO}

A proposta deste artigo é relatar o processo de desenvolvimento do evento inclusivo In-Palco. O In-Palco teve como proposta, por meio da acessibilidade e inclusão, a criação de estratégias de comunicação direcionada, utilizando-se da manifestação artística e cultural, na tentativa de despertar o estímulo para incluir todos os públicos e excluir barreiras que impossibilitem qualquer pessoa a exercer seus direitos básicos. O método adotado para a execução da proposta de evento inclusivo foram as fases do processo de planejamento, que de acordo com Matias (2004), são: concepção; pré-evento; trasnevento e pós evento. O evento foi realizado em 2019, no município de São Borja, RS. A Mostra contou com o apoio de 39 empresas locais, a presença de uma intérprete de Libras e do SAMU, além de rampa acessível e local para deficientes auditivos sentirem a vibração sonora. Foram nove cidades participantes, inclusive da Argentina, 400 bailarinos, sendo 40 com deficiência, 64 coreografias e 328 quilos de alimentos arrecadados. Nesse sentido, o evento proporcionou uma experiência de evento a partir das ferramentas estratégicas do campo da comunicação e das relações públicas, utilizando-se da dança como temática central. O evento impactou diretamente, de maneira positiva, na qualidade de vida, acesso e garantia dos direitos das pessoas com deficiência e com mobilidade reduzida.

Palavras-chave: Acessibilidade; Comunicação; Estratégias de relacionamento; Pessoas com deficiência.

\section{ABSTRACT}

The purpose of this article is to report the development process of the In-Palco inclusive event. In-Palco had as a proposal, through accessibility and inclusion, the creation of targeted communication strategies, using artistic and cultural expression, in an attempt to awaken the stimulus to include all audiences and exclude barriers that make it impossible for anyone to exercise their basic rights. The method adopted for the execution of the inclusive event proposal were the phases of the planning process, which, according to Matias (2004), are: conception; pre-event; trasnevento and post event. The event was held in 2019, in the city of São Borja, RS. The Exhibition had the support of 39 local companies, the presence of an interpreter from Libras and SAMU, in addition to an accessible ramp and a place for the hearing impaired to feel the sound vibration. There were nine participating cities, including from Argentina, 400 dancers, 40 with disabilities, 64 choreographies and 328 kilos of food collected. In this sense, the event provided an event experience based on strategic tools in the field of communication and public relations, using dance as a central theme. The event had a direct positive impact on the quality of life, access and guarantee of the rights of people with disabilities and reduced mobility.

Keywords: Accessibility; Communication; Relationship strategies; Disabled people.

1 Relações públicas. Mestra e Doutora em Comunicação. Professora Adjunta do curso de Relações Públicas da Universidade Federal do Pampa - Campus São Borja - RS. Líder do grupo de TELAS pesquisa colaborativa CNPq. Email: fernandaandres@unipampa.edu.br

2 Relações Públicas. Email: carolmoreirarp@gmail.com 


\section{INTRODUÇÃO}

Eventos, de maneira ampla, são oportunidades em diferentes áreas, como o turismo, marketing e relações públicas, que utilizam dessa ferramenta para atingir objetivos singulares. Existem diversos tipos de eventos, com diferentes objetivos, ferramentas e públicos, como os organizacionais, eventos sociais, promocionais, e, dentre eles, há o evento inclusivo. $\mathrm{O}$ evento inclusivo é um assunto pouco discutido e com baixo índice de referências teóricas, todavia, este tipo de evento possui a mesma finalidade de um evento qualquer, mas, certamente, deve contar com a introdução da acessibilidade na sua produção e execução.

O In-Palco foi uma dessas ações materializadas a partir da produção de evento inclusivo. A atividade consistiu em uma mostra de dança sem caráter competitivo, que buscou refletir a problemática da falta de acessibilidade em eventos na cidade de São Borja - RS, através da comunicação acessível e da arte. O intuito do In-Palco foi de produzir e divulgar um evento inclusivo, tendo como elemento principal a dança, para pessoas com deficiência residentes do município de São Borja - RS e região. Para tanto, buscou-se: (1) despertar a reflexão acerca da questão social através da comunicação e da dança; (2) incentivar à prática da inclusão em todos os eventos e ações do município de São Borja; (3) gerar mudanças positivas na qualidade de vida do público com deficiência; e (4) possibilitar uma nova estratégia de comunicação direcionada.

O In-Palco teve como proposta, por meio da acessibilidade e inclusão, a criação de um evento inclusivo, utilizando-se da manifestação artística e cultural, na tentativa de despertar o estímulo para incluir todos os públicos e excluir quaisquer barreiras que impossibilitam qualquer pessoa a exercer seus direitos básicos. Concomitantemente, o evento procurou incentivar a participação de todos e todas em projetos inclusivos e a realização de denúncias por falta de acessibilidade.

\section{REFERENCIAL TEÓRICO}

\section{EVENTOS NA ÁREA DE RELAÇÕES PÚBLICAS}

Compete ao profissional de relações públicas o gerenciamento estratégico da comunicação, empenhando-se em estabelecer relacionamentos transparentes e duradouros com os diversos públicos. De acordo com Roberto Porto Simões, o evento, como instrumento de relações públicas, pode ser definido como "acontecimento criado com a finalidade específica de alterar a história da relação organização-público, face às necessidades observadas. Caso ele não ocorresse, a relação tomaria rumo diferente e, certamente, problemático" (SIMÕES, 1995, p. 170). 
Considerando o poder significativo de engajar diferentes tipos de pessoas numa ideia ou ação, utiliza-se do evento como ferramenta estratégica da comunicação integrada, pois, desta maneira, possibilita a segmentação do público de interesse para transmitir uma mensagem específica, promovendo interação e integração em torno de uma mesma ideia. Para Ferracciù,

A grande força de um evento reside no envolvimento que ele permite. A atmosfera criada, a atenção despertada, a curiosidades, a predisposição de espírito, tudo, enfim, conduz a um envolvimento coletivo apropriado que condiciona positivamente o participante e que nenhum outro recurso de promoção consegue fazer (FERRACCIÚ, 1997, p. 70).

Para Isabela Cavalheiro e Larissa Rodrigues (2013, p. 4), “evento pode ser caracterizado de diferentes formas: por objetivo ou área de interesse, com relação ao público (eventos fechados ou abertos), por abrangência, por data e frequência", podendo então, ser tipificado de diversas maneiras.

A resolução normativa $\mathrm{n}^{\circ}$ 43, de 24 de agosto de 2002, atribui as atividades de relações públicas à aplicação de conceitos e técnicas de comunicação estratégica, com a finalidade de alcançar, de maneira eficaz, os objetivos gerais e específicos para a instituição. A comunicação dirigida utiliza-se de instrumentos que percorrem por interesse comuns para atingir seus públicos. A comunicação integrada, por sua vez, visa assegurar uma atuação sinérgica no processo de comunicação com as concorrências dos diferentes setores de comunicação. Todos os conceitos supracitados são pertinentes na elaboração e satisfação de um evento.

De acordo com o Conselho Federal de Profissionais de Relações Públicas - CONFERP, algumas das funções e atividades privativas dos profissionais de relações públicas giram em torno de "conceber, criar, planejar, implantar e avaliar eventos e encontros institucionais que tenham caráter informativo para construir e manter imagem".

Cabe ao profissional de relações públicas criar, atentamente, o planejamento do evento, considerando às necessidades dos diversos públicos de interesse. Deve-se ter como base o planejamento estratégico da instituição ou organização, incluindo o evento como parte do plano estratégico comunicacional. De acordo com Cesca (2008), para obter um resultado eficaz e atingir plenamente seus objetivos é fundamental que, no planejamento do evento, critérios minuciosos sejam desenvolvidos, como: objetivos, públicos, estratégias, recursos, implementação, fatores condicionantes, acompanhamento e controle, avaliação e orçamento.

A gestão do evento deve ser especificamente cautelosa para certificar o desempenho das ações pensadas e garantir a qualidade no relacionamento entre os públicos, assim como gerar reciprocidade no respeito e confiança. Embora o evento seja, de certa forma, operacional no seu modelo de execução, ele requer uma boa análise crítica com ideias criativas e pensamento estratégico, tanto no momento de seu planejamento como de sua concepção. 


\section{EVENTO INCLUSIVO E ACESSIBILIDADE}

A definição de Evento Inclusivo no campo acadêmico não é muito fomentada até o momento, porém, pensando no significado e importância de eventos citados até aqui, tanto no contexto sociocultural como no ambiente da comunicação, devemos, cada vez mais, nos preocupar com esse tipo de evento, tendo em vista que pessoas deficientes integram a sociedade, são consumidores de serviços públicos ou privados, tornando-os assim, possíveis públicos de interesse.

A palavra incluir, de acordo com o Dicionário Aurélio da Língua Portuguesa (2004, p 469. ), significa "conter ou trazer em si; compreender, abranger; fazer tomar parte; inserir, introduzir" e Sassaki apresenta a definição de inclusão como "modificação na sociedade para torná-la capaz de acolher todas as pessoas" (SASSAKI, apud LIMA, 2006, p. 24). Assim, podemos entender que inclusão é uma forma de inserção social, levando em consideração as necessidades do indivíduo como problema social, na busca pela transformação da sociedade e não a adequação do sujeito na sociedade.

A Lei Federal n $10.098 / 2000$, estabelece normas gerais e critérios básicos para a promoção da acessibilidade das pessoas com deficiência ou com mobilidade reduzida.

Deficiência é a ausência ou a disfunção de determinada estrutura, sendo elas: psíquica, fisiológica ou anatômica.

A deficiência é um conceito em evolução; ela é resultado da interação entre pessoas com impedimentos (físicos, mentais, intelectuais ou sensoriais) e as barreiras devidas às atitudes e ao ambiente que impedem a plena e efetiva participação dessas pessoas na sociedade em igualdade de oportunidades com as demais pessoas. (CONVENÇÃO SOBRE OS DIREITOS DAS PESSOAS COM DEFICIÊNCIA, 2014, p. 16).

Entendendo acessibilidade como condição de viabilização da inclusão social, segundo as normas brasileiras é

a condição para utilização, com segurança e autonomia, total ou assistida, dos espaços, mobiliários e equipamentos urbanos, das edificações, dos serviços de transporte e dos dispositivos, sistemas e meios de comunicação e informação, por pessoa portadora de deficiência ou com mobilidade reduzida (DECRETO 5.296 de 2004, Art 8).

Considerando as pessoas com deficiência como também um público de interesse, devemos introduzir e criar mais eventos e ações voltados para a participação desse público, com o objetivo de sanar as dificuldades e barreiras existentes. Deve-se cumprir medidas apropriadas para assegurar às pessoas com deficiência o acesso a oportunidades de maneira igualitária para com os demais sujeitos nos mais variados setores da vida social, como em eventos, mercado de trabalho, meio físico, transporte, informação ou comunicação, entre outros. 


\section{COMUNICAÇÃO ACESSÍVEL EM EVENTOS}

Evento, de forma ampla, é conceituado como uma ferramenta de comunicação aproximativa entre instituição e público de interesse. Waldyr (2003), afirma que os eventos são um dos principais serviços de prestação de informações, porém a comunicação para o evento em questão deve ser feita de forma planejada e eficiente, caso contrário, não atingirá os objetivos esperados. Utiliza-se de diferentes ações para a efetivação dessa comunicação de acordo com o consumo de ferramenta do seu público, como por exemplo: assessoria de imprensa; facebook; rádio; tv; jornal; instagram; banners; cartazes; folhetos; campanhas; teaser; outdoor; jingle; VT e entre outros.

No que se trata de comunicação acessível, a existência de barreiras na comunicação e no acesso a informação é incontestável, gerando dificuldades para pessoas com deficiência sensorial ou intelectual na participação de um evento ou em diversas outras atividades.

Comunicação acessível de acordo com Art 3 Lei No 13.146, de 6 de julho de 2015 trata-se da

forma de interação dos cidadãos que abrange, entre outras opções, as línguas, inclusive a Língua Brasileira de Sinais (Libras), a visualização de textos, o Braile, o sistema de sinalização ou de comunicação tátil, os caracteres ampliados, os dispositivos multimídia, assim como a linguagem simples, escrita e oral, os sistemas auditivos de comunicação, incluindo as tecnologias da informação e das comunicações. (BRASIL, 2015).

Em relação a comunicação através de produtos audiovisuais, recursos como a autodescrição, legenda oculta e a janela do intérprete de LIBRAS, são fundamentais para proporcionar qualidade de vida através do acesso à informação e comunicação para esse grupo social. A audiodescrição é

\footnotetext{
o recurso que consiste na descrição clara e objetiva de todas as informações que compreendemos visualmente e que não estão contidas nos diálogos, como, por exemplo, expressões faciais e corporais que comuniquem algo, informações sobre o ambiente, figurinos, efeitos especiais, mudanças de tempo e espaço, além da leitura de créditos, títulos e qualquer informação escrita na tela. (AUDIODESCRIÇÃO, 2011). ${ }^{3}$
}

A audiodescrição não atende somente pessoas com deficiência visual, mas também pessoas com deficiência intelectual, com dislexia e até mesmo idosos com dificuldade para enxergar.

Além da audiodescrição, ainda existe a possibilidade de legenda, que é a transcrição em língua portuguesa do áudio do produto comunicacional. Salienta-se que legenda oculta é um tipo de legenda que transcreve exatamente a fala e sons apresentados em produções audiovisuais, também conhecida como closed caption. A janela de libras é um espaço na tela em que há um interprete fazendo a mediação do conteúdo passado no audiovisual. Os dois recursos permitem a compreensão do assunto por pessoas com deficiência auditiva.

3 Disponível em: http://audiodescricao.com.br/ad/o-que-e-audiodescricao/. Acesso em: 10 abr. 2019. 
Dos meios de comunicação por elementos impressos, existem letras ampliadas, braile, versões eletrônicas e lembretes de descrição. A partir desses elementos pode-se realizar uma comunicação acessível e eficaz para a realização de eventos ou qualquer tipo de ação que necessite do acesso a informação.

\section{METODOLOGIA}

\section{PLANEJAMENTO DE EVENTO}

Planejamento de evento compõe-se do processo de identificar qual situação uma instituição/ organização está e para onde ela pretende ir, assim definindo quais táticas ou estratégias estabelecer para alcançar seus objetivos. O planejamento é uma ferramenta de gerenciamento, onde o gestor de eventos precisa estar consciente que, para realizar um planejamento eficaz, diversos pontos precisam ser analisados, tais como: monitoramento e avaliação do andamento; coordenar tarefas e tomadas de decisões em todas as atividades, além de despertar o interesse, motivar as equipes responsáveis pela execução do plano para que o evento seja realizado com sucesso.

Para uma garantir a satisfação nos resultados, deve-se atentar que o planejamento é um documento que precisa ser consultado e adaptado com frequência, pois existem diferentes fatores e circunstâncias que podem alterar o segmento do plano. Assim sendo, os planos devem estar adaptados à dinâmicas para alterações.

Segundo Matias (2004, p. 111), as fases do processo de planejamento e organização de eventos são: a) concepção; b) pré-evento, c) per ou transevento; e d) pós-evento.

\section{Concepção}

É a fase inicial de todo evento, momento de formular ideias e tomar as primeiras decisões para a elaboração de um evento. A autora Matias (2002) destaca alguns pré-requisitos necessários, como: identificação dos objetivos (gerais e específicos); coleta de informações sobre os públicos envolvidos; listagem dos resultados desejados; estimativa de execução econômica e técnica, estimativa de tempo e recursos necessários, listagem dos resultados desejados, estabelecimento de diretrizes e elaboração dos contornos dos projetos.

\section{Pré-evento}

O planejamento é a fase decisiva no pré-evento, no qual são inseridos a coordenação executiva e os controles financeiros do evento. É importante que nessa etapa a descrição das atividades sejam pontuadas para servir de subsídio de toda a execução e auxiliar no controle do desenvolvimento do projeto. Apontar todas as ações do evento é a forma mais segura de garantir a eficácia na sua reali- 
zação. Para Martin (2003, p. 45) "Planejar o evento é ganhar agilidade no desempenho, é melhorar a eficiência na execução de tarefas, é mensurar com mais acuidade os resultados e ter referências para avaliá-los". Com um bom planejamento, as estratégias de ações são definidas, são reduzidos os esforços e tarefas, imprevistos são menos recorrentes e mais fáceis de serem contornados, além de evitar o desperdício de tempo e recursos.

O planejamento engloba o levantamento de dados e informações, os objetivos, recursos, despesas e cronograma citados no estágio I, para, posteriormente, no estágio II, definir as estratégias, local, data, programação e outros. No estágio III, é a materialização do evento. O estágio IV é o feedback do evento e a apreciação dos resultados finais.

De forma geral, as etapas do planejamento devem ser feitas de forma bem detalhadas, contudo, devem zelar pela objetividade e clareza das ideias.

Quando se espera obter melhores resultados e um evento bem executado é imprescindível que o planejamento seja realizado da melhor forma possível; é importante também que se faça a seleção das atividades mais urgentes e prioritárias, e se estabeleça um cronograma detalhado com a definição das equipes envolvidas e o responsável de cada área (MANTUAN, 2014, p. 32).

Um fator importante a ser destacado é que os benefícios do planejamento aumentam de acordo com a dimensão do evento, ou seja, quanto maior o evento, mais planejado e elaborado o plano deve ser. A descrição dos detalhes das atividades e execução devem estar ainda mais especificadas e pontuadas em todas as áreas.

Elaborado devidamente, o planejamento deve contemplar a definição de todas as estratégias e providências necessárias para o evento, abrangendo os gastos, serviços e colocar em práticas tudo o que já foi estipulado.

\section{Per ou Transevento}

Essa fase corresponde à realização no desenvolvimento do evento. É a aplicação das determinações citadas no pré-evento, local onde tudo foi pensado, estruturado, planejado, programado, contratado e será colocado em prática. É a fase decisiva do evento, em que estão inseridos a coordenação executiva, o controle financeiro, técnico-administrativo e social do evento.

\footnotetext{
A gestão do evento deve ser cuidadosa para garantir tanto o cumprimento das ações planejadas quanto o bom relacionamento entre os diversos públicos envolvidos, para que haja respeito e confiança mútua, além do comprometimento de todos com a proposta do evento (FARIAS 2011, p. 148).
}

A realização do evento é o momento em que o público irá interagir e participar de tudo o que o evento se propôs a oferecer. O que difere um evento do outro é forma de organização e criatividade no momento da elaboração de propostas que mantenham um contato direto com as pessoas de forma efetiva, de maneira que façam com que elas se transformem em um público, simultaneamente. 
Áreas importantes devem ter um cuidado redobrado pela organização, como recursos eletrônicos, materiais, equipamentos de som e mídia, que são usados durantes todo o período do evento. Assim, caso ocorra algum imprevisto, como danificação ou mal funcionamento de algum material, deve-se estar atento para repor esse tipo de equipamento. Outro setor de suma importância é a recepção e atendimento dos participantes e convidados. Saber receber e orientar o público são prioridades no evento e, em caso de dúvidas, devem ser sanadas da melhor forma possível.

Matias (2002) destaca alguns detalhes importantes que devem ser considerados a respeito da realização do evento: secretaria do evento; serviço de recepção; "clima” do evento; sala de recepção ou sala VIP; sala de imprensa; sala das comissões técnicas; infraestrutura de apoio operacional; infraestrutura de apoio externo; e pesquisa de opinião.

Se tudo for realizado conforme o planejamento do evento e a equipe estiver devidamente preparada, a programação tende a acontecer de forma natural, com grandes chances de atingir os objetivos do evento e a satisfação dos públicos.

\section{Pós-Evento}

O processo de encerramento inicia-se assim que encerra a realização do evento. Ele consiste na desestruturação do local e da avaliação técnica, administrativa e dos participantes. É através desse momento que ocorre a verificação dos resultados obtidos, possibilitando identificar pontos positivos e negativos do evento.

Logo após a conclusão do evento, algumas atividades devem ser encerradas de forma cautelosa, como a desmontagem de equipamentos, realização de serviço de secretaria e divulgação do pós-evento, conferir materiais alugados ou emprestado e efetuar a devolução. Também deve-se atentar para os serviços financeiros, como: pagamentos de materiais ou serviços, notas fiscais e balanço administrativo e financeiro do evento.

Assim, para que se obtenha uma avaliação eficaz sobre o evento, é importante que seja registrada a opinião dos participantes, de maneira que evidencie as insatisfações e possa auxiliar na construção de próximos eventos. Segundo Cesca (1997, p. 31) “a avaliação da organização desses tipos de encontros ficará mais adequada se houver subsídios de uma avaliação do evento feita junto ao público participante".

Desta forma, conclui-se que o trabalho de organizar um evento, seja ele de qualquer categoria, é muito complexo e minucioso. Lidam com fatores e recursos essenciais para realização, que devem ser previamente planejados para atingir os devidos objetivos. Portanto, na organização de um evento, a dedicação e empenho são fundamentais, assim como colaboradores qualificados e gestores responsáveis, tanto aos prazos quanto às atividades propostas. 


\section{RESULTADOS E DISCUSSÃO}

O método adotado para a execução da proposta de evento inclusivo foram as fases do processo de planejamento que, de acordo com Matias (2004), são: Concepção; Pré-evento; Transevento e Pós-evento.

Durante o pré-evento, foram pontuados todos os subsídios para a execução e desenvolvimento do projeto. Todas as ações, listadas a seguir, foram executadas de forma planejada e organizada, com o intuito de gerar o menor número de imprevistos e garantir a eficácia na realização. Criação da marca; desenvolvimento de oficinas; formação de parcerias e patrocinadores; criação do regulamento; criação da plataforma de inscrição; produção de social media; divulgação; assessoria de imprensa; produção de material; capacitação da equipe de apoio e ambientação do local.

A divulgação do projeto deu-se de forma acessível por mídias on e off-line, disponibilizando vídeos em Libras, áudio-descrição (antes e durante o evento) além da descrição das imagens veiculadas nas redes sociais digitais, aderindo à campanha \#pracegover. Especificamente sobre a campanha, ela foi criada pela professora brasileira, Patrícia Braille, como forma de conscientizar as pessoas videntes de que as pessoas cegas também precisam ter acesso às imagens. Usando essa hashtag, as pessoas com deficiência visual conseguem pesquisar nas plataformas os conteúdos com descrição e utilizar os leitores de tela para poderem ver as imagens. A proposta é traduzindo imagens em palavras. Esse é o sentido da descrição que vem logo depois da hashtag.

A campanha \#pracegover consistiu em despertar a atenção dos usuários para que coloquem uma descrição detalhada da imagem utilizada em suas publicações em mídias sociais. Essas informações foram disponibilizadas em todas as produções visuais, sendo útil para pessoas com dislexia, deficiência intelectual, deficiência visual ou com déficit de atenção. O evento foi realizado no dia 10 de agosto de 2019, das 13h às 20h30min, no auditório do Colégio Sagrado Coração de Jesus.

A entrada foi franca com a opção da doação de alimento, o qual foi destinado para a Casa da Acolhida de São Borja, local que abriga crianças e adolescentes em vulnerabilidade social. Salienta-se que uma equipe preparada para receber e orientar o público esperado - pessoas com deficiência - auxiliou durante a organização e execução do In-Palco. A Mostra contou com o apoio de 39 empresas locais, a presença da intérprete de Libras da Universidade Federal do Pampa, campus Itaqui-RS, Bruna Todeschini, enfermeiros do SAMU e também do Hospital Ivan Goulart, além de rampa acessível e local para deficientes auditivos sentirem a vibração sonora.

Em números, os resultados podem ser percebidos na participação de 9 cidades, entre elas as gaúchas: São Borja, Santiago, São Luiz Gonzaga, Cruz Alta, Saldanha Marinho, Passo Fundo, Porto Alegre; e duas Argentinas: Posadas e Santo Tomé. O evento contou com a apresentação de 400 bailarinos, sendo 40 com deficiência. Além do mais, 64 coreografias foram apresentadas para uma plateia de mais de 500 pessoas. E $328 \mathrm{~kg}$ de alimentos foram arrecadados e doados para instituição social. 
Nesse sentido, o evento proporcionou uma experiência de evento a partir das ferramentas estratégicas do campo da comunicação e das relações públicas, utilizando-se da dança como temática central.

A repercussão do projeto se deu em diversas frentes: internet, imprensa e comunidade. No ambiente digital, vários comentários positivos foram recebidos através da fanpage. Além do mais, a imprensa local ofereceu vários espaços de entrevistas na rádio, matérias nos jornais e publicações de influenciadores digitais., as organizadoras do In-Palco foram convidadas a receber uma homenagem na Câmara de Vereadores de São Borja. Os resultados oriundos do evento In-Palco nas publicações em jornais e entrevistas na rádio, obteve um total de R\$10.035,00 em mídia espontânea. E por fim, em 2020, o projeto recebeu o Prêmio Nacional Expocom, na categoria: Projeto de Relações Púbicas. O reconhecimento nacional, resultou na inserção do evento no calendário oficial do município de São Borja.

\section{CONSIDERAÇÕES FINAIS}

Através do evento In-Palco, sendo esse o primeiro evento inclusivo com a comunicação acessível e a dança como elemento principal de interação e inclusão de todos os públicos realizado na cidade de São Borja-RS, foi possível evidenciar as barreiras que ainda existem no acesso aos direitos básicos das pessoas com deficiência, assim como refletir a respeito da inclusão em eventos e demais setores sociais da população são-borjense.

Além disso, observou-se como a comunicação acessível é elemento fundamental para alcançar e integrar todos os públicos, salientando a importância de incluir as pessoas com deficiência em todas as ações voltadas a população são-borjense.

A mostra de dança também demonstrou como a manifestação artística, principalmente a dança, possui a capacidade de superar os limites que, de certa forma, algumas deficiências impõe aos indivíduos. A cidade de São Borja, que, recentemente, recebeu o título de Capital Gaúcha do Fandango, embora conhecida pelos festejos da semana farroupilha, onde ocorrem diversas apresentações com as CIAs de Dança e Invernadas, não é comum as apresentações de coreografias com dançarinos com algum tipo de deficiência.

O intuito do In-Palco foi mostrar que pessoas com deficiência também podem e devem estar inseridos nesses meios e, concomitantemente, incentivar a prática da inclusão em todos os eventos e ações do município. O evento impactou diretamente, de forma positiva, na qualidade de vida, acesso e garantia dos direitos das pessoas com deficiência e mobilidade reduzida, já que se evidenciou a satisfação, alegria e emoção dos participantes, além da melhoria na questão de inclusão nos eventos, ações e espaços presentes na cidade.

Durante o desenvolvimento do evento, ficou claro a falta de ações voltadas para o público com deficiência, já que há pouco material bibliográfico que verse sobre esse assunto. Por outro lado, notou-se a vontade de mudar esse paradigma, visto que a comunidade são-borjense apoiou a causa e 
reagiu com gratidão pelo aspecto positivo que o evento foi capaz de proporcionar na vida das pessoas que prestigiaram o In-Palco.

\section{REFERÊNCIAS}

BRASIL. Decreto-Lei 5.296, de 2 de dezembro de 2004. Regulamenta as Leis nos 10.048, de 8 de novembro de 2000, que dá prioridade de atendimento às pessoas que especifica, e 10.098, de 19 de dezembro de 2000, que estabelece normas gerais e critérios básicos para a implementação da acessibilidade das pessoas portadoras de deficiência ou com mobilidade reduzida, e dá outras providências.

Diário Oficial República Federativa do Brasil, Brasília, DF, 2 de dezembro de 2004.

BRASIL. Lei $n^{\circ}$ 10.098, de 19 de dezembro de 2000. Estabelece normas gerais e critérios básicos para a promoção da acessibilidade das pessoas portadoras de deficiência ou com mobilidade reduzida, e dá outras providências. Diário Oficial da República Federativa do Brasil, Brasília, DF, 19 de dezembro de 2000.

BRASIL. Lei $n^{\circ}$ 13.146, de 6 de julho de 2015. Institui a Lei Brasileira de Inclusão da Pessoa com Deficiência (Estatuto da Pessoa com Deficiência). Diário Oficial da República Federativa do Brasil, Brasília, DF, 6 de julho de 2015.

CAVALHEIRO, Isabela. RODRIGUES, Larissa F. O papel do Relações Públicas na Organização de Grandes Eventos. In: CONGRESSO DE CIÊNCIAS DA COMUNICAÇÃO NA REGIÃO SUDESTE, 18, v. 1, 2013, Bauru. Anais... Unesp Bauru: 2013, p 1-10.

CESCA, Cleuza GG. Organização de Eventos: Manual para Planejamento e Execução. São Paulo: Editora Summus, 1997.

FARIAS, L A. Relações Públicas Estratégicas: técnicas, conceitos e instrumentos. São Paulo: Summus, 2011.

IBGE. Indicadores de pessoas com deficiência na cidade de São Borja, segundo Censo Demográfico de 2010. Acesso em 22 de abril de 2018. Disponível em: https://bit.ly/2YZW0I1.

MATIAS, Marlene. Organização de Eventos. São Paulo: Manole, 2002.

MATIAS, Marlene. Organização de eventos: procedimentos e técnicas. Barueri: Manole, 2004. 
MARTIN, Vanessa. Manual Prático de Eventos. São Paulo: Atlas, 2003.

SASSAKI, R.K. Inclusão, o paradigma da próxima década. Brasília: Mensagem, 1998.

SIMÕES, Roberto Porto. Relações Públicas: função política. São Paulo: Summus, 1995. 